\title{
Erector Spinae Block
}

\author{
Rashmi Singh'Surinder Singh ${ }^{1}$ Arindam Choudhary ${ }^{1}$ Sandeep Sharan ${ }^{1}$ Milind Padmakar Hote ${ }^{2}$ \\ Poonam Malhotra Kapoor ${ }^{1}$
}

1Department of Cardiac Anaesthesia, CTC, AlIMS, New Delhi, India52154156

J Card Crit Care 2021;5:154-156.

2Department of CTVS, CTC, AlIMS, New Delhi, India

A novel interfascial plane block, erector spinae plane (ESP) block, has been utilized for postoperative pain management in a variety of surgical procedures as well as for relief of acute and chronic pain. As this is a relatively newer technique, there is paucity of literature, and most knowledge stems from case reports and small randomized trials.

\section{Technical Aspects}

ESP block is applied mostly between T5-T7 paraspinal level; however, lower spinal level can also be chosen for initial site of application. Linear, high-frequency USG probe is placed 2 to $3 \mathrm{~cm}$ lateral to T5 spinous process and trapezius; rhomboid major and erector spinae muscle are then identified superficial to transverse process. Block needle is inserted superior to USG probe from cephalad to caudal direction, using in plane approach. Once the needle tip is between erector spinae and transverse process, a small bolus of normal saline is injected to appreciate proportional hydrodissection. After confirmation of hydrodissection, 20 to $30 \mathrm{~mL}$ of $0.2 \%$ ropivacaine or $0.25 \%$ bupivacaine is injected bilaterally ( - Figs. 1 to 7 ). ${ }^{1}$

\section{Clinical Significance}

Pain management, especially postsurgical ones, has always been a matter of grave concern for anesthesiologists. Poor pain management has many untoward complication like tachycardia, pulmonary infection, delayed weaning from ventilators, and poor respiratory effort; hence, it leads to poor surgical outcomes. Wide practice of fast-track surgery and enhanced recovery after surgery (ERAS) program demands effective pain control after surgery.

Conventional methods of pain control include systemic use of various nonsteroidal anti-inflammatory drugs (NSAIDS) and opioids. Excessive use of NSAIDS can cause bleeding, various thromboembolic and gastrointestinal (GI)

published online August 5, 2021
DOI https://doi.org/

10.1055/s-0041-1732842

ISSN 2457-0206
Address for correspondence Poonam Malhotra Kapoor, MD, DNB, MNAMS, FICTA (Hony), FTEE (Hony), FISCU (Hony) Department of Cardiac Anaesthesia, CTC, AlIMS, New Delhi, India (e-mail: drpoonamaiims@gmail.com).

complications, as well as acute kidney injury (AKI). Likewise, opioids can also cause tolerance, dependence, nausea, vomiting and respiratory depression in a dose-dependent fashion.

The possibility of providing satisfactory pain relief without causing adverse side effects from systemic analgesics gives rise to the necessity of alternative pain relief technique. ESP is an interfascial plane block, which provides extensive multidermatomal sensory block, with proposed site of action being ventral and dorsal thoracic rami, causing anesthesia of posterior, lateral and anterior thoracic wall. Use of USG has made institution of this block relatively safe and convenient. It can be performed as a single injection or via continuous catheter placement. Various case reports have demonstrated its utility in providing analgesia, ranging from chronic shoulder pain to pain following hip surgery. ${ }^{2,3}$

\section{Review of Literature}

ESP block was first practiced by Forero et al in the successful management of chronic neuropathic pain in patients who were not responding to oral pharmacotherapy ${ }^{4}$ To show the extent of spread of local anesthetic, Forero et al analyzed the extent of spread by CT, both in patients and in cadavers. On injecting $25 \mathrm{~mL}$ of local anesthetic superficial to erector spinae muscle at T5 level, a cephalocaudal spread from T1 to T11 was noted.

Hamilton and Manickam successfully applied continuous ESP block in patients with multiple unilateral rib fractures. ${ }^{5}$ They stated that local anesthetic is injected at close proximity of costotransverse foramina, which is the site of origin of dorsal and ventral rami, explaining its extensive spread

ESP block has also been used safely and effectively in breast surgery, abdominal surgery, and spine fusion. ${ }^{6-8}$

As far as cardiac surgery is concerned, successful application of this block has been there in both thoracotomies and sternotomies. A randomized control study (RCT) conducted (c) 2021. Official Publication of The Simulation Society (TSS), accredited by International Society of Cardiovascular Ultrasound (ISCU).

This is an open access article published by Thieme under the terms of the Creative Commons Attribution-NonDerivative-NonCommercial-License, permitting copying and reproduction so long as the original work is given appropriate credit. Contents may not be used for commercial purposes, or adapted, remixed, transformed or built upon. (https://creativecommons.org/licenses/by-nc-nd/4.0/). Thieme Medical and Scientific Publishers Pvt. Ltd. A-12, 2nd Floor, Sector 2, Noida-201301 UP, India 


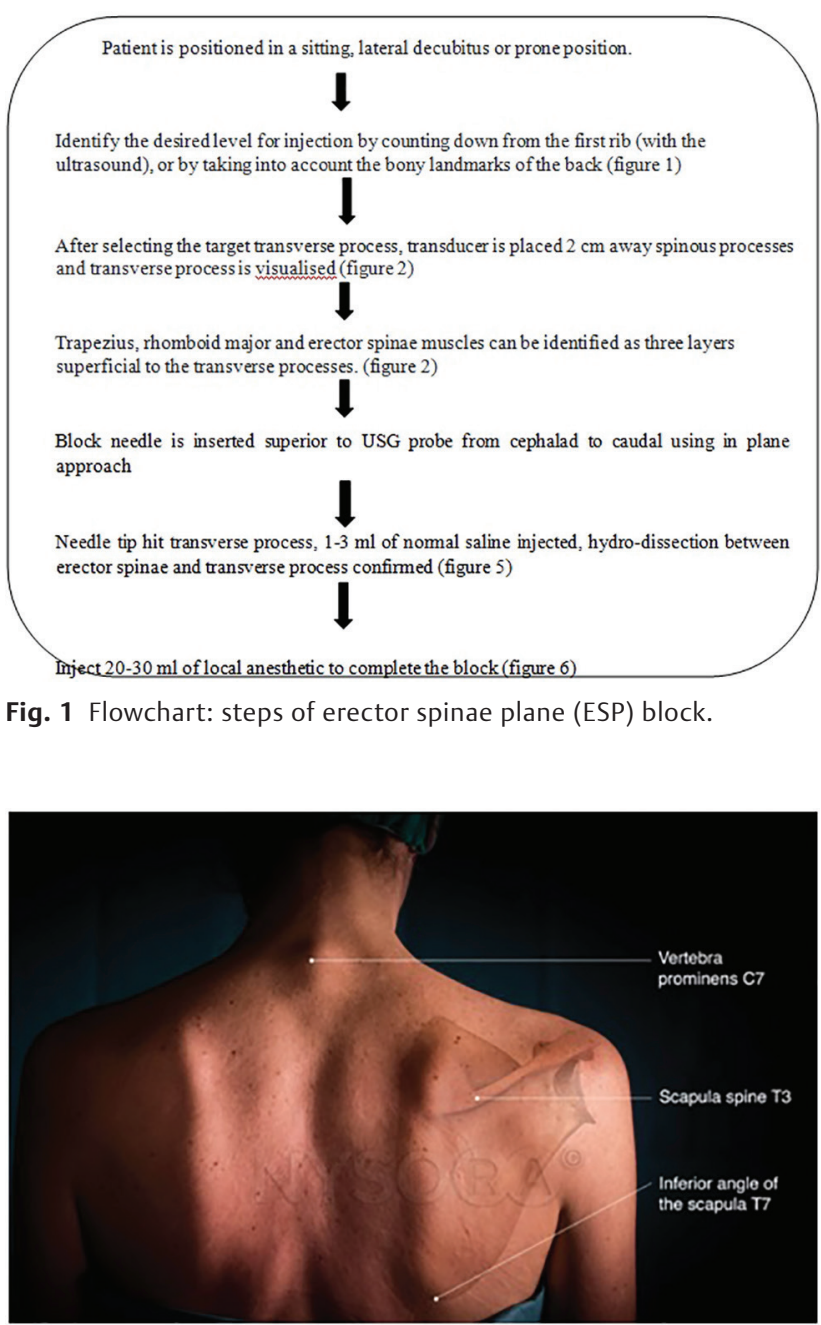

Fig. 2 Anatomical landmark pertaining to erector spinae plane (ESP) block.
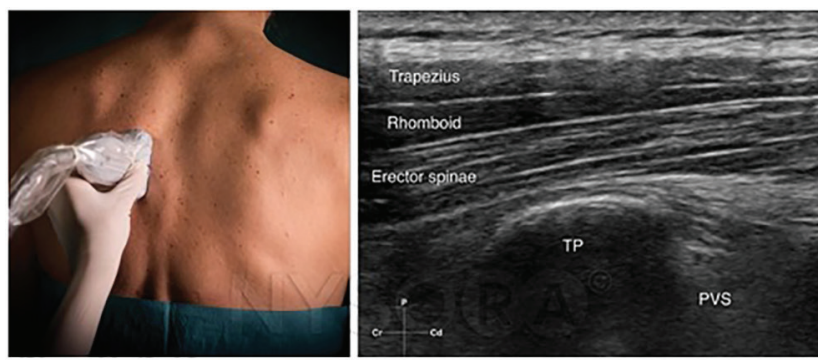

Fig. 3 Position of ultrasound probe and sonographic visualization of muscle layer.

by Krishna et al, using bilateral ESP block in adult cardiac surgical patients undergoing surgery via midline sternotomy, concluded that ESP block provides satisfactory and more durable analgesia than conventional parenteral analgesics. ${ }^{9}$ The median pain after extubation till 12 hours postextubation was significantly lesser (numerical rating scale $[N R S]<4)$ in ESP group than control.

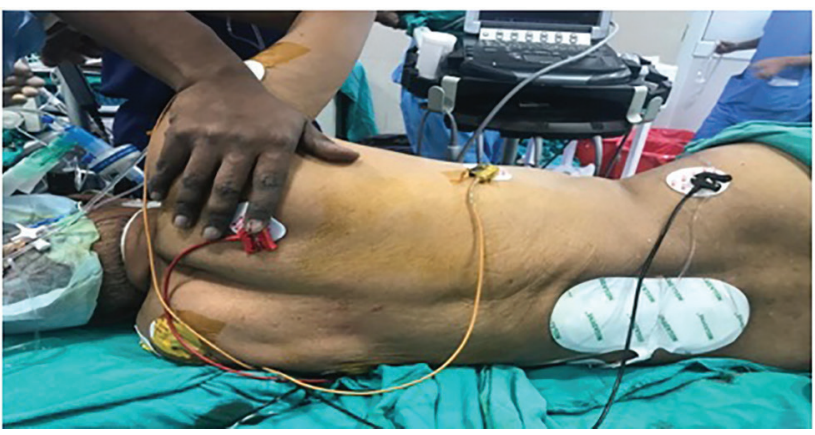

Fig. 4 Lateral decubitus position for block.

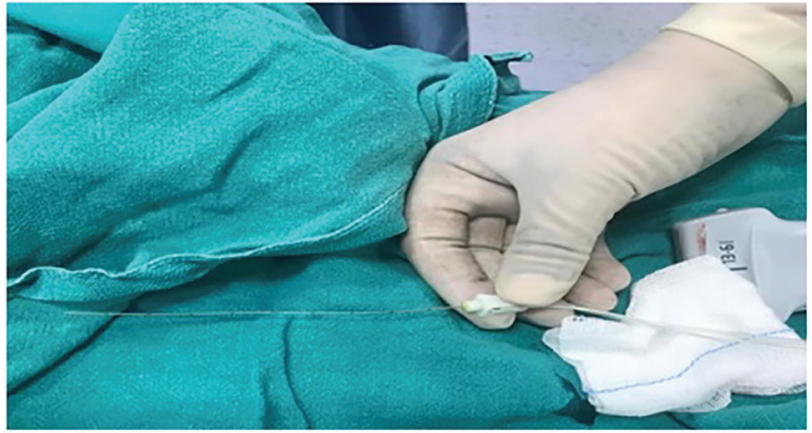

Fig. 5 Block needle.

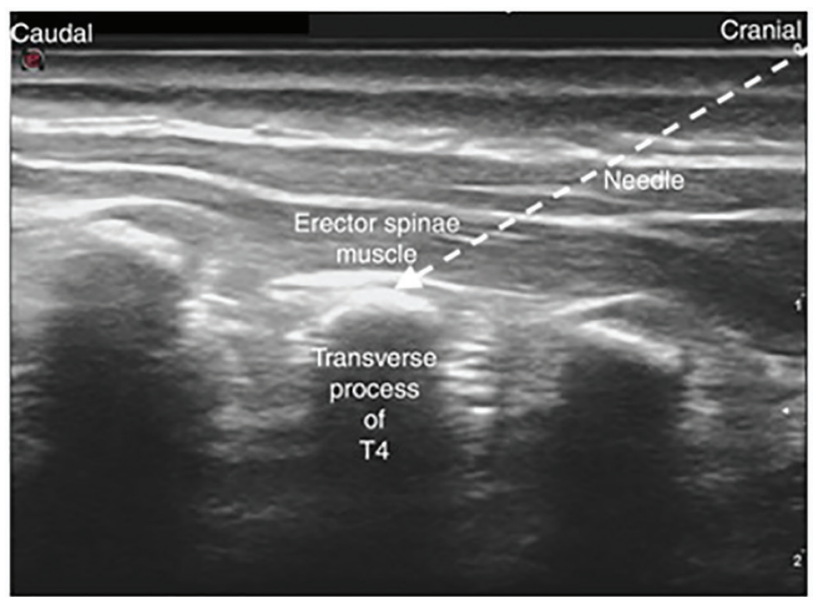

Fig. 6 Position of needle tip between erector spinae plane (ESP) muscle and transverse process.

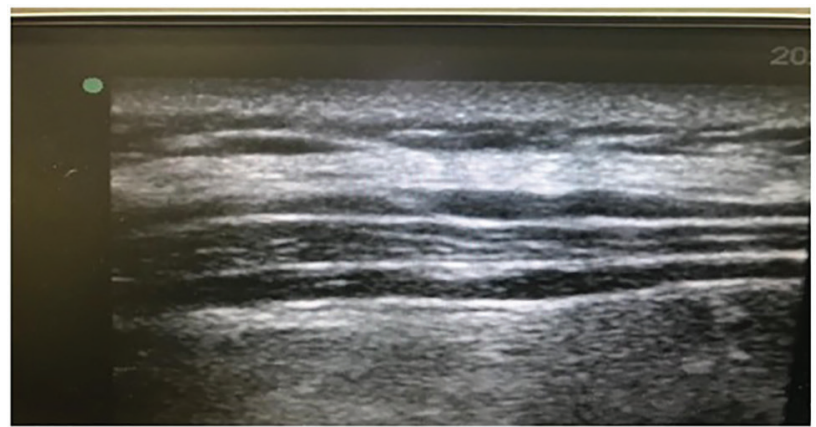

Fig. 7 Separation of fascia between erector spinae plane (ESP) and transverse process. 
Forero et al reported the efficacy of continuous ESP block in successful pain management of patients undergoing surgery via thoracotomy and in whom epidural has failed. ${ }^{10}$

\section{Conclusion}

There is limited data present on utility of regional anesthesia in combating poststernotomy pain. ESP block has been applied in cardiac surgery with midline sternotomy, but more study needs to be done to further prove its utility.

However, results of this block is encouraging and has been associated with better pain relief, lesser opioid consumption, and overall lower length of hospital stay.

\section{Conflict of Interest}

None declared.

\section{References}

1 Krishnan S, Cascella M, Erector Spinae Plane Block. Treasure Island (FL): StatPearls Publishing; 2021
2 Forero M, Rajarathinam M, Adhikary SD, Chin KJ. Erector spinae plane block for the management of chronic shoulder pain: a case report. Can J Anaesth 2018;65(3):288-293

3 Bugada D, Zarcone AG, Manini M, Lorini LF. Continuous Erector Spinae Block at lumbar level (L4) for prolonged postoperative analgesia after hip surgery. J Clin Anesth 2019;52:24-25

4 Forero M, Adhikary SD, Lopez H, Tsui C, Chin KJ. The erector spinae plane block: a novel analgesic technique in thoracic neuropathic pain. Reg Anesth Pain Med 2016;41(5):621-627

5 Hamilton DL, Manickam B. Erector spinae plane block for pain relief in rib fractures. Br J Anaesth 2017;118(3):474-475

6 Gürkan Y, Aksu C, Kuş A, Yörükoğlu UH, Kılıç CT. Ultrasound guided erector spinae plane block reduces postoperative opioid consumption following breast surgery: A randomized controlled study. J Clin Anesth 2018;50:65-68

7 Tulgar S, Selvi O, Kapakli MS. Erector spinae plane block for different laparoscopic abdominal surgeries: case series. Case Rep Anesthesiol 2018;2018:3947281

8 Chin KJ, Lewis S. Opioid-free analgesia for posterior spinal fusion surgery using erector spinae plane (ESP) blocks in a multimodal anesthetic regimen. Spine 2019;44(6):E379-E383

9 Krishna SN, Chauhan S, Bhoi D, et al. Bilateral erector spinae plane block for acute post-surgical pain in adult cardiac 